\section{Handy Book on Cancer Genetics Risk Assessment}

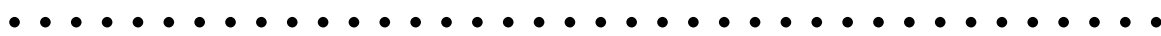

Lallao E, Kerr B, Friedman J, Evans G (eds). Oxford University Press, Oxford, UK, 2005.

ISBN 0-19-852960-0

..........

Ulf Kristoffersson

European Journal of Human Genetics (2006) 14, 888.

doi:10.1038/sj.ejhg.5201641

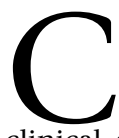

ancer genetics has, during the past 10 years, been more or less an established subspecialty of clinical genetics and oncology involving as well the clinical geneticists as oncologists, surgeons and other stakeholders in the cancer care team. Moreover, as the clinical improvement has been very much in parallel to new research results, it has also involved laboratory scientists in clinical care to a greater extent than has been usual in health care; the close collaboration between the clinician examining the patient and the scientist interpreting the laboratory findings is one of the most important prerequisites for introducing molecular medicine into clinical practice. This plethora of stakeholders with different educational backgrounds has created a need for bridging textbooks covering the basics of clinical cancer genetics, and this book 'Risk Assessment and
Management in Cancer Genetics', edited by Lallao, Kerr, Friedman, and Evans, is the latest in this series.

This book is divided into three parts: Introduction, Risk assessment of common malignancies, and Rare cancer syndromes. The four introductory chapters give an overview of risk assessment for cancer families, the evaluation of family history in a British/European and North American/ US perspective, and the principles of genetic testing for some common cancers. Part two consists of seven chapters dealing with the risk assessment, genetic testing, and management of common malignancies in more detail; chapter 8 on breast cancer is even divided into two parts giving a European and a North American perspective of breast cancer management. The third part consists of six chapters of which five deal with the management of one rare cancer syndrome each, whereas the sixth sums up the management of some other rare hereditary cancer syndromes. The last chapter of the book discusses ethical and insurance aspects of cancer genetic counselling.

The four editors have, including themselves, assembled a great number of leading cancer genetic clinicians and scientists among the authors of the different chapters. The majority are of British or North American background and therefore the management and risk assessment principles mainly reflect the practices in these countries. However, these principles are in line with the practices in many other countries, and thus reflect an unofficial international consensus. The book is very educational; all chapters are interfoliated with Boxes, with bullet points extracting the most important issues. It includes practical guidance and shows examples of simple methods for the estimation of cancer risk to healthy relatives in suspected cancer families. However, as a minor remark, the last chapter on ethics and insurance would have fitted better in part one than in part three.

The book is very valuable for the practicing doctors, and it is an excellent tool for medical staff in specialist training, for the non-cancer genetic medical specialist who wants to know cancer genetic management principles, and for all other professionals who want to have a handy book available in their consultation room

Ulf Kristoffersson is at the Department of Clinical Genetics, University Hospital, Lund SE-221 85, Sweden Tel: + 46461733 63; Fax: + 4646131061 ; E-mail: Ulf.Kristoffersson@med.lu.se 